\title{
Indigenous Islamic Food: An Ideal Product Innovation for Creativity in Cultural Tourism: A Case Study Khao Tung Pla (Thai Crispy Rice Crackers with Anchovies)
}

\section{Nopparat Boonpienpon}

Candidate Doctor of Philosophy Program in Tourism and Hospitality Innovation Management Faculty of Management Science, Khon Kaen University; Email:furnmba@hotmail.com

\section{Thirachaya Maneenetr}

Director of Center for Asia-Pacific Tourism Research, Faculty of Management Science, Khon Kaen University Email: thirachaya@kku.ac.th

Phitak Siriwong

Dean, Faculty of Management Science Silpakorn University Phetchaburi IT Campus Email: innjun@yahoo.com

\section{Donruetai Kovathanakul}

Lecturer in Tourism Department, Faculty of Management Science, Khon Kaen University Email: som910@hotmail.com

Doi:10.5901/mjss.2015.v6n5s2p445

\section{Abstract}

This article offers a critique of indigenous food which has the potential to add many benefits and much creativity to cultural tourism. Food is one of the four requirements for human survival. The tourism industry is that in which tourists partake in the local food produce. The World Tourism Organization (UNWTO) forecasts the growth of the tourism industry by the year 2030 to reach 1.8 billion international tourists globally. The UNWTO further points out that most popular tourist places will specifically be those of the Asia and Pacific regions. Thailand is considered one of the most popular countries within a popular continent; however, the significant task of tourism in Thailand remains as to how to attract greater numbers of international tourists to the country. This leads us to one of the activities in which all tourists partake during their trips to Thailand, namely eating. Hence, food is an alternative tourist activity with which to specifically attract tourists. This is especially the case for indigenous food which can be presented from its cultural aspect, in addition to it being an exotic and authentic experience for visitors. This article emphasizes the indigenous food in the Andaman region of Thailand where the cuisine is mostly local Islamic food. This food is that produced by the native people in an area well-known for its Muslim community. Therefore, the local cuisine is not only presented as a food product, but also as an integral part of the culture of the native people. In other words, this local Islamic food could present the international tourist with the culture of the locals, their way of life, and the uniqueness of Thai identity through the consumption by tourist themselves.

Keywords: Indigenous Food, Cultural Tourism, Creativity and International Tourists.

\section{Introduction}

Food is integral to human life and everybody needs to consume it. Yet aside from being a daily requirement, food also represents the uniqueness of a place. In particular, indigenous food is accompanied by the uniqueness of the food product. Indigenous food is local food made by local people. Therefore, indigenous food presents the local methods of cooking, local ingredients, and sometimes even a unique method of consumption. Indigenous food is very popular, nowadays, especially in terms of tourism. Many tourists are willing to spend their money in order to get the good quality food they want. This has given rise to a new form of tourism by its attraction of tourists for food consumption. Tourists not only see the indigenous food, but also experience the local people and way of life, and so on. This leads to the addition of indigenous food as part of the tourism business. This can be considered a form of Alternative Tourism whereby tourists engage in a variety of activities and travel experiences. The tourism industry is becoming popular among many countries 
due to the benefits that it brings to the whole country. The tourism business brings with it a lot of value to the country such as income, employment, infrastructure development, education, environmental awareness and the country's reputation itself. However, many countries compete in trying to create a variety of activities and means of tourism in order to attract visitors to their country.

Therefore, indigenous food could be one alternative form of tourism in terms of Cultural Tourism. Recently, many countries have been trying to present indigenous food as a kind of Cultural Tourism in order to entice international tourists to visit. Indigenous food consumption is presented to the tourist in a variety of aspects and activities such as cooking classes, eating classes, or even a more complete indigenous food package. This is supported by the many researchers who have studied indigenous food and how to use it in the tourism business. Tourism Queensland (2003) pointed out the important role of food in tourism and concluded that food could leave the tourist with an impressive experience of their trip and this could in turn create an Alternative Tourism industry globally. Moreover, Chang et al. (2011) conducted research on food tourism and found that another way to satisfy the international tourists is to present them with a cuisine; as many tourists love to indulge in great food with a good taste during their trip. Therefore, indigenous food is an alternative form of Cultural Tourism which could be an alternative experience for international tourists and the tourism country itself.

\section{Objectives of the Study}

1) Study the expectations of local populations for Thai crispy rice with anchovies.

2) Study tourists' satisfaction with Thai crispy rice crackers with anchovies.

\section{Literature Review}

The researcher studied additional information based on the following concepts, theories, and related researches:

\subsection{Identity of local Islamic food}

In this research, the researcher talks mainly about Ching-Chang fish or anchovies. Anchovies are considered an economic product of the Andaman Sea. This kind of fish is the same as the one called Ka-tak in the Central part of Thailand. An anchovy is a small, common salt-water forage fish and normally lives in groups. Its body is slender and flat on the sides, with barbs on its belly. Its upper jaw extends to the rear of its eyes. It has a single rear fin and a deep round fish tail with blue stripes along its body. There are a lot of fisheries of anchovies in the Andaman Sea as this kind of fish is one of the top money-making exports of Thailand. This kind of fish can be exported to every region of Thailand and also outside the country, especially, in Asian countries such as Malaysia, Singapore, Brunei, etc. There are many kinds of anchovies, from the smallest white ones which are normally called Bora or Bura by fishermen to the biggest ones, both white and those rather dark in color.

To preserve anchovies, they need to be washed with clean water and boiled in water heated on a big cement stove before adding big lumps of salt. After boiling them until they turn white and float up, they are taken out of the pot and put in a basket to be dried. Finally, the fish are put on a dense net to be exposed to the sunlight until they are dried. During the hot season such as in March or April, it takes about eight hours to complete the process and the fish can be sold right away. However, if there is not much sunlight or if the monsoon season comes, it may take a longer time and more salt should be put on them. The fish should be kept free of humidity; otherwise, they will be spoiled. The producers must wake up early to examine the fresh anchovies to be used in the cooking process and sunned. If any procedure is neglected or done carelessly the fish will not be fresh and therefore will be distasteful and dried out. The wholesale prices may vary during different periods depending on the quality of the fresh fish. If the fish are high quality, the price will be high, and it also depends on the size of the fish which can vary from small sizes to medium to large and jumbo respectively. Moreover, anchovies are exported to neighbor countries such as Malaysia and China. Although some provinces on this side of the gulf of Thailand also have dried anchovies, the taste different. The anchovies in the Andaman Sea and the gulf of Thailand have the following differences: those in the Andaman Sea are more oily because of the fresh fish are frozen before being boiled while those in the gulf of Thailand are normally salted, which increases the weight of the fish, but when it is fried, it doesn't swell and is more salty.

\subsection{Marketing composition and value added creations for tourism}

Marketing Mix The concept of "Marketing Mix" was introduced for the first time by Borden (1964). It was referred to as the 
4Ps, comprising four factors of marketing mix; Product, Price, Place, and Promotion (McCarthy, 1960; Perrault \& McCarthy, 2004). Nonetheless, there is a limitation in using the 4Ps concept to analyze current businesses which are modern and service oriented. Consequently, other scholarsexpanded marketing mix by adding several factors for analysis. Booms and Bitner (1981) added more factors from4Ps to 7Ps to make them more appropriate for consumer needs. The added three factors were People, Process, and Physical Evidence. Lovelock and Wirtz (2004) enhanced more marketing mix factors from 4Ps to 8Ps to better reflect present service business, comprising: 1) Product - goods and services developed and produced to meet the needs of customers in order to create the highest satisfaction, including brand, packaging, guarantee, product and quality development (Needham, 1996; Armstrong \&Kotler, 2005), 2)Price - price is what customers spend to get desired goods or services and the goal of price setting is to create competitive advantages to the extent that a company gains profits and customers can afford the goods and services, 3)Place - the selling process and the support of product distribution which make goods and services available for sale, and that require the development of distribution channels appropriate with the product, service, and target markets (Needham, 1996; Perrault \& McCarthy, 2004), 4) Promotion - setting up communication guidelines with target customers about the product, service, price, and other information to encourage their decisions to buy products and services by using promotional mix such as advertising, public relations, sales promotion, direct marketing, and personal selling (Needham, 1996), 5) People - every single person involved in the product and service selling process, including employees and customers who make a purchase or are service users, 6) Process - service providing steps or processes, regulations and how the job is done to create and promote goods and services to customers, for example, making a decision on customers and the firm's personnel policies, 7) Physical evidence - an environment associated with service providing; the place where customers and business providers interact, and any tangible components that facilitate or communicate that service, and 8) Productivity and Quality of Service - factors affecting the productivity and quality of the service industry such as service quality, customer satisfaction, provider satisfaction, ability to meet customers' needs, ability to resolve customers' problems, modern tools and equipment and service quality assurance.

In conclusion, all factors from the marketing mix (10 P's: 1.Product, 2.Price, 3.Place, 4.Promotion, 5.Process, 6.People, 7.Physical Evidence, 8.Productivity, 9.Positioning of Brand / Product, and 10.Perception) were used to set up questions in the questionnaire about the effects of expectations of local populations for Thai crispy rice crackers with anchovies.

\subsection{Innovation}

There have been widely conducted studies about innovation, but none of them are accepted generally. Some studies considered the expenses used in research and development (R\&D) or data from a patent (Breschi, 1999; Malerba\&Orsenigo, 1995), while others considered whether a new thing is an innovation or not.

According to literature reviews by many economists, there are many types of innovations using in a variety of ways, especially technological innovations, such as making the production process dramatically different. Some say that products and process could be changed slowly and gradually. According to Lundvall (1992), innovation is a continuous change in order to have new products, techniques, and markets.

Avermaete et al. (2003) compiled two concepts of innovation, initiated by Clarysse et al. (1998) and Lundvall (1992), and then divided the innovation into four types, namely: product innovation, process innovation, organizational innovation, and market innovation, all of which are interrelated.

1) Product innovation means new products or services or new ideas derived from a person or everyone in an organization. Also, it can originate from the change of organizational structure. At times, we find that most of the products sold in general markets are alike or just slightly different, so entrepreneurs, both existing and new, turn to focus on pricing strategies in order to attract more customers, as well as increase sales. At present, the intensified pricing competition tends to be a major obstacle for entrepreneurs to run and plan their businesses. Especially, SME entrepreneurs, who have a limitation of capital, capacity, and labor, are unable to produce a large number of products. Thereby, the product costs per unit are higher compared to major operators who gain benefits from economy of scale. In addition, major operators tend to bring in business innovations in order to increase value added for products and services and to display their products' uniqueness and difference from other similar products or services available in markets by presenting higher quality and higher value products for customers. However, not only is innovation a tool for making a product different, it can also improve the product and its production process to decrease production cost and time spent in operation, which contributes to the capacity in market competition for a long-term business.

2) Process innovation means the improvement of existing production lines by installing new additional 
infrastructures and technologies. In general, process innovation brings about the creation of new products and is a part of the changes in the new organization. This contributes to the growth of new markets. Both innovation and production process are critical to the success of environmentally friendly production.

3) Organizational innovation means changes in marketing, administration, management, and working policy. Organizational innovation is important in every industry; high quality and standardized organizations have fine product and process innovations and, therefore, have a competitive advantage.

4) Market innovation means accessing new markets in order to find benefits or profits from gaining more marketing shares.

Katz (2003) explains that there are two types of innovation: incremental innovation and radical innovation. Incremental innovation occurs when the existing technologies or materials are improved or adapted before use. On other hand, radical innovation is derived from non-existent technologies or methods. Some prefer using the term "breakthrough innovation and discontinuous innovation" rather than radical innovation. Clayton Christensen (Christensen, 1997) from Harvard University uses the term "disruptive technology" to explain that some technological innovations went extremely against certain businesses or industries. Disruptive technology replaces and then deteriorates existing technologies. On the contrary, at times disruptive technology is able to bring about new markets. The new markets may be small at the beginning, but they are likely to grow later.

Moreover, Katz (2003) states that process innovation and service innovation are as important as product innovation because process innovation can decrease the cost of production by removing discontinued or outmoded steps. Furthermore, the link between product and process is important because some innovative products require innovative processes to attract customers to make purchases.

Furthermore, service innovation plays an important role in market success. In the past, not only could the company sell products constructed through innovations, but also the company or organization could provide services already invented through successful innovations. However, this does not mean that all service providers were successful. Some companies went bankrupt and quit operating their businesses. Even though a company may have a good concept for a service, the company is likely to go bankrupt due to failure to provide services, as well as high cost of investment.

Rak (2004) divides innovation into three facets:

1) Product innovation means the development of new products, technologies or process, or the improvement of existing things for more efficiency. The characteristics of the innovation can be anywhere from incremental to radical.

2) Process innovation means the application and the change of a process in production, method, and service, as well as organization management. Overall, process innovation depends upon the ability to change, or adjust an organization at every point of the value chain with the purpose of enhancing efficiency and effectiveness, leading to an advantage in marketing competition.

3) Managerial or administrative innovation means an invention in organizational management which increases the efficiency of a working system, production, product design, and service.

To sum up from the researcher's perspective, innovation can be mainly categorized as follows: product and service innovation, process innovation including production technology, service, and information technology, and administrative technology including administration in finance, personnel, marketing, and organizational culture, etc.

\section{Research Methodology}

\subsection{Population and sample}

Implementation of the study found that Thai crispy rice crackers with anchovies are one of the best choices for this research area. The implementation study was separated into two parts, expectations of local populations and satisfaction of International tourists with Thai crispy rice crackers with anchovies, where both were presented with significant outcomes. For data analysis of the marketing factors that affect expectations of local populations for Thai crispy rice crackers with anchovies, perspective was gained from a sampling groupof 100 participants (approximately $10 \%$ of 760 responses from the questionnaire for the local population in the study areas) and data analysis from the general information of tourists' satisfaction with Thai crispy rice crackers with anchovies from a sampling group of 50 participants(approximately $10 \%$ of 400 responses from the questionnaire for International tourists)

1) Local population in the study areas consisted of 50 local sub-populations in the areas of Yao Island and Panyee Island, PhangNga Province. These sub-populations participated in the administration of a questionnaireto analyze qualitative data. A total of 100 local people in the study areas of Yao Island and 
Panyee Island were selected for SPSSanalysis statistics. These statistics will be used to analyze the quantitative data.

2) Touristsincluded 50 individuals selected for the research sample who were traveling on Yao Island or Panyee Island in PhangNga Province. A questionnaire was used to collect quantitative data.

\subsection{Research area}

The study area covers the shoreline along the Andaman Coast on Yao Island and Panyee Island in PhangNga Province, Thailand. These areas are very famous tourist spots amongst tourists in Thailand. Moreover, it is evident that these areas represent characteristics of the Islam community, especially due to the Islamic population that has been settled along the Andaman coast for a long time and their significant local culture

\section{Research Result}

\subsection{Data analysis of the general information of the local population}

Frequency and percentage of the local population regarding expectations for Thai crispy rice crackers with anchovies by gender in dicates that most participants(72) were female, for an average of $72 \%$, and 28 were male, for an average of $28 \%$, respectively. Classification by age group reveals that most participants (26) were people aged between 31-35 years old which was $26 \%$, followed by 18 participants aged between $41-45$ years old at $18 \%$. Another 16 participant's age did not exceed 25 years which was $16 \%$. Classification by marital status reveals that most participants (66) were married, totaling 66\%; 28 participants were single totaling 28\%; and six participantswere divorced, at 6\%. Classification based on education reveals that most survey participants(44) were people with a High School level education, being 44\%; 32 people had a Bachelor's Degree, totaling 32\%; and 22 people had Elementary level or lower, at $22 \%$. Classification based on occupation reveals that most survey participants (46) had occupations in agriculture, totaling 46\%; 27 people were business owners, at 27\%; and ten people were government employees, which was $10 \%$.Classification based on monthly income reveals that 36 survey participants had a salary range from 10,001-15,000 Baht, totaling 36\%; 29 people had a salary range from 15,001-20,000 Baht, at 29\%; and 28 people had a salary range of less than 10,000 Baht, which was $28 \%$. Classification by length of stay in the area reveals that 63 participants have stayed in the area for more than 25 years, totaling 63\%; 14 people have stayed between $21-25$ years, at 14\%; and eight people have stayed between 16-20 years, which was $8 \%$

\subsection{Local poplations' expectations for Thai crispy rice crackers with anchovies in the overall perspective}

Table 1. Mean nd standard deviation of local poplations'expectations for Thai crispy rice crackers with anchovies in the overall perspective

\begin{tabular}{lccc}
\hline Marketing factors that affect the expectations of local populations for & \multicolumn{3}{c}{ Level of expectation } \\
Thai crispy rice crackers with anchovies & $\bar{x}$ & S.D. & Interpretation \\
\hline 1. Product & 4.37 & 0.42 & Highest \\
2. Price & 3.98 & 0.91 & High \\
3. Place & 3.97 & 0.82 & High \\
4. Promotion & 4.01 & 0.81 & High \\
5. Process & 4.52 & 0.56 & Highest \\
6. People & 3.84 & 0.94 & High \\
7. Physical Evidence & 4.01 & 1.02 & High \\
8. Productivity & 4.19 & 0.97 & High \\
9. Positioning of Brand / Product & 4.24 & 0.83 & Highest \\
10. Perception & 4.35 & 0.78 & Highest \\
\hline Total & 4.22 & $\mathbf{0 . 3 9}$ & Highest \\
\hline
\end{tabular}

Table 1 shows the local populations' expectations for Thai crispy rice crackers with anchovies in the overall perspective was rated highest ( $=4.22)$; considering the three highest rates shows expectations for process ( =4.52), product ( $=4.37$ ), and perception ( $=4.35)$, respectively. 


\subsection{Data analysis on the general infomation of tourists'satisfaction with Thai crispy rice crackers with anchovies}

Data analysis on the general information of tourists'satisfaction with Thai crispy rice crackers with anchovies from a sampling group of 50 participants is shown. Frequency and percentage of tourists responding to a survey on satisfaction with Thai crispy rice crackers with anchovies by gender indicates that most survey participants(26) were female, totaling $52 \%$; and 24 were males, at $48 \%$.Classification by age indicates that most tourist participants (12) were between 36-40 years old, totaling 24\%; followed by 11 people between 31-35 years old, at 22\%; and ten people between $41-45$ years old, which was $20 \%$.Classification based on marital status indicates that most tourist participants (31) were married, totaling 62\%; 13 peoplewere single, at 26\%; and five people were divorced which was $10 \%$.Classification by education level shows that most tourist participants(31) had a Bachelor's Degree totaling 62\%; 15 people had a Master'sDegree, at $30 \%$; and two people had a Doctoral Degree,which was 4\%. Classification based on monthly income (per month in THB) shows that most tourist participants(17) were people that havea monthly income of 20,001-30,000 Baht, totaling 34\%; followed by 16 people with a monthly income of 40,001-50,000 Baht, at 32\%; and nine people with a monthly income higher than 50,000 Baht, which was $18 \%$.Classification by occupation shows that most tourist participants (23) were business owners and state enterprise employees, totaling 46\%; followed by 19 people who were employees or a Chief Executive Officer,at 38\%; and seven people who were government officers, which was $14 \%$. Classification based on religion shows that most tourist participants (30) were Christian, totaling 60\%; followed by 17 people who were Islamic,at $34 \%$; and three people whowere Buddhists, which was $6 \%$.Classification by homeland shows that most tourist participants (34) were people from Asia, totaling 68\%; and 16 people were from Europe, at $32 \%$. Classification by nationality shows that most tourist participants (10) were Chinese totaling 20\%; followed byeight Germans, at 16\%; both Korean and Malasian nationalities shared the same frequency of seven people, which was $14 \%$.

Table 2. Mean and standard deviation of tourists'satis faction with Thai crispy rice crackers with anchovies in the overall perspective

\begin{tabular}{lccc}
\hline Satisfaction & \multicolumn{3}{c}{ Satisfaction Level } \\
& $\bar{X}$ & S.D. & Interpretation \\
\hline 1. Sensory Attributes & 3.86 & 0.39 & High \\
2. Health Concerns & 4.03 & 0.48 & High \\
3. Methods of Preparation and Cooking & 3.63 & 0.60 & High \\
4. Value and Quality & 3.96 & 0.62 & High \\
5. Authentic Tourist Experience & 4.23 & 0.47 & Highest \\
\hline Total & 3.96 & $\mathbf{0 . 2 5}$ & High \\
\hline
\end{tabular}

Table 2 shows a highleveloftourists'satisfactionwith Thai crispy rice crackers with anchovies in the overall perspective ( =3.96). Examining the highest to lowest ratings, the data suggests that tourists'had the highest satisfaction with the authentic tourist experience $(=4.23)$; followed by health concerns $(=4.03)$, value and quality $(=3.96)$, sensory attributes ( $=3.86)$, and preparation and cooking methods ( $=3.63)$, respectively.

\section{Discussion}

After brainstorming and using the workshop results to establish a suitable innovation pattern for Cultural Tourism management for use at the present time, the researcher, government and private corporation representatives, restaurant entrepreneurs, and local people of Ko Yao (Yao Island) and Ko Punyi (Punyi Island) have proposed developing Chingchang fish or Anchovies to be used as a topping under the brand name "Khao Tang Pla (Thai crispy rice crackers with anchovies)". We focused on using organic and unique local ingredients like anchovies to create a distinctive healthy Islamic snack and to promote local tourism.

A Thai crispy rice cracker is an antique traditional snack. It can be found in many famous Thai food cultures and at present is still quite popular. Rice crackers remain one of the original recipes that lives on. This snack can be modified to fit many dining styles such as crispy rice cake with dip (Khao Tang Nha Thang), crispy rice cake with a special recipe coconut sauce (Khao Tang Mieng Lao), and crispy rice crackers with chicken floss, etc.

"Khao Tang Pla" (Thai crispy rice crackers with anchovies) is a co-developed product between the researcherand the Panyee and Koh Yao communities. The team collaborated and experimented with three recipes to come up with this valuable product. 
In the final experiment, the researcher used Riceberry rice to satisfy customers with health concerns. The team used the same $5 \times 9 \mathrm{~cm}$ rectangle shape for the Riceberry cracker and again deep fried them before adding the same syrup and crispy anchovy powder. This recipe adds more value to the product since the ingredients are varied and have more nutrients. Riceberry rice has recently become famous among Thai heath conscious customers due to its many benefits. It helps to prevent and cures diseases as its quality is compared with that of top quality brown rice. Despite having many minerals such as antioxidants, beta-carotene, gamma oryzanol, vitamin-e, tannin, zinc, high folic, it contains less sugar than other rice. Besides using Riceberry rice for food, medical experts have developed alternative food therapies from it as well. These are some of the reasons why Riceberry is such a good choice.

Using Riceberry as the basic ingredient and combining it with traditional recipes of rice crackers and the unique flavor of anchovies, we have blended some of the finest ingredients to use for the heritage menu. Not only will health benefits be provided to customers but this also opens the opportunity for business development and additional employment for local communities. Other communities can create their own recipes by adapting Riceberry to their natural ingredients, customer demand or to fit their own needs.

Crispy Riceberry crackers are made with Riceberry rice, premium jasmine rice (new), sticky rice (with a ratio of 3:2:1), water and salt. The following are the preparation instructions: First, mix the jasmine rice, sticky rice, Riceberry rice, and $a$ bit of salt together and stir until they are blended. Afterward spread the rice onto a flat container and wait until it is completely sun-dried, the sun-dried rice sheets must be cut into rectangular shapes before they are deep fried. The two most important steps of cooking the rice crackers are the sun-drying and frying; frying enables the crackers to become crispy and not sticky. Moreover, a perfectly done cracker has a delicate aroma and beautiful color. Another thing to keep in mind is the thickness of the cracker sheets; all the cracker sheets must be of the same thinness so when frying those sheets, they will get evenly crisp. Using moderate to low heat and a good amount of boiling oil will make the cracker sheet cook instantly. Do not wait until it turns yellowish brown because the sheets will shrink. The desired color is a beautiful light golden color. The anchovy topping is powdered following the traditional recipes from the community and sprinkled on top of the Riceberry cracker. The rice crackers should be completely dry before packing them into their sachets.

To market this product, put each rice cracker into a perfect fit sachet. Afterwards those sachets can be packed in decorative boxes that are suitable as gifts or those appropriate for health conscious consumers. Khao Tang Pla's logo displays the symbols of the Muslim community and their beliefs which are stars and a crescent moon. Packaging has the symbol of a fish that resembles the crescent moon to indicate its distinctive ingredients. The green background color is derived from the antiquated Germanic language word "grene" from the same root words "grass" and "grow" which indicates "growth". Green is the color of nature or the natural environment. It is popular for nature and organic products and has become quite a trend for people interested in eco-culture. City people view green as a color that can enrich their lives health-wise and environmentally.

The packaging design of "Khao Tang Pla" is built on the concept of ease of transporting. The container must be shockproof, convenient, compact, modern, and fascinating .Each package will contain 8 sachets which are perfect as a souvenir. Moreover, "Khao Tang Pla" will create brand awareness of Halal standard food for every nation and religious customer worldwide. The main priority is safety and quality in production. We employ staff who are local people in the community and people who have expertise on Halal.

In terms of Promotion, customers can seek more information about the crispy rice cracker with anchovies from the website and Facebook. Word of mouth advertising about its taste is also encouraged to increase the interest of tourists to try the product.

Our findings from this research add value to the product by way of cultural storytelling, local customs, and creativity. These findings are based on the FCC theory (FCC = Food $x$ Culture $\times$ Creativity). It is hoped that this research product will lead to a possible marketing of the product because now food is not only about nutrition but also about aesthetics.Simply put, nowadays people also eat with their "eyes" before they actually "taste" the flavor of the food. In brief, it is a matter of customer satisfaction.

\section{Conclusion}

With above described of the result of study that Thai crispy rice crackers with anchovies would be a best practice product under the identity of particular study area. This created the cooperation among people within the community through their planning, implementation, benefits and evaluation of the outcome. The concept of Product Development creates the image of good health, and may be interpreted as symbolic for food, starfish, and the moon. Price Development creates standardization of pricing in the community, especially for those international tourists. Place Development identifies the 
point of sale; such as convenience stores within the Prunai municipality, located within the study area. Promotion development endeavors to create confidence and trust among international tourists as consumers. Process Development represents the preparation of the Thai crispy rice crackers with anchovies would incorporate the true Halal process, performed by Muslim chefs. The next development in the study, People Development; addresses the mixture of the local Muslim community with the target market, the international tourist. This could create the great value of local Muslim community among international tourists. The last development is that of Physical Evidence Development, in which the concept 'Easy to go around the word' has been created.

The results of the implementation study found that Thai crispy rice crackers with anchovies is one of the best products to use for this research area. The implementation study was divided into two parts; the expectations of the local community and the satisfaction of international tourists regarding Thai crispy rice crackers with anchovies and both were presented with significant outcomes.

The overall expectations of the local community regarding Thai crispy rice crackers with anchovies were at the high level ( =4.22); examininghe highest to lowest ratings indicat that most of the local community havethe highest expectationsforThai crispy rice crackers with anchovies in terms of process $(=4.52)$, product $(=4.37)$ and the perception of the product $=4.35$ ) respectively. Moreover, the study further disclosed that the overall satisfaction of international tourists toward Thai crispy rice crackers with anchovies was at the highest level of $=3$.96. When examiningthe highest to lowestratings, the dataindicates that most international tourists'satisfactionis concerning having the feel of an authentic tourist experience $(=4.23)$, health concerns $(=4.03)$, value and quality $(=3.96)$, sensory attributes $(=3.86)$ and method of preparation and cooking $(=3.63)$ respectively.

Further investigating the highest level of the overall expectations of the local community regarding Thai crispy rice crackers with anchovies, it was found that the process involving Thai crispy rice crackers with anchovies was the first area of concern of the local community and lot of attention has been focused on it. The reason behind this attention is due to all the community being Muslim so they are very much concerned about Halal, therefore, the production process of Thai crispy rice crackers with anchovies should be in line with the principles of Halal food as well. The second attribute that most of the local community was concerned about was product.The product in this sense refers to anchovies which represent their local community. The result of this concern has brought them to the idea of creating a logo for Thai crispy rice crackers with anchovies that could represent the identity of their community. Therefore, the logo of Thai crispy rice crackers with anchovies in this study was presented with a Muslim identity as the core concept. Perception was the third highest attribute which held the interest of most of the local community. Most of the local community wanted to use Thai crispy rice crackers with anchovies to play an important role in others' perception of the community. They expressed the opinion that Thai crispy rice crackers with anchovies should be developed with as a high-quality processed food product in line with the principles of Halal food. Thai crispy rice crackers with anchovies could help consumers to be able to eat food products with confidence that they met safety standards.

For the most part, the results of international tourists' satisfaction regarding Thai crispy rice crackers with anchovies were presented in the highest level. It showed that most international tourists were satisfied with Thai crispy rice crackers with anchovies in terms of Authentic Tourist Experience. The sense of this authenticity can be defined in terms of all the information about Thai crispy rice crackers with anchovies which could be searched with the use of technology, the Internet, or even online social networks. Moreover, tourists also can be encouraged to consume Thai crispy rice crackers with anchovies by word of mouth. There should be development and implementation of easy to buy souvenirs of high-quality, processed products of Thai crispy rice crackers with anchovies in order to present the identity of the area as well.

The result of this study s to expand the awareness of both the researcher and the local community in terms of a presentation process of Thai crispy rice crackers with anchovies through Internet online social networks that could be a significant tool for international tourists. Moreover, the first step of product development from the local community's perspective is product establishment and presentation via Internet, online and social networks consecutively; this could establish a reputation for Thai crispy rice crackers with anchovies and raise awareness among international tourists.

Next, it was found that most international tourist are very concerned with health and the quality of products, hence, the study has introduced Riceberry an appropriate health conscious product. Riceberry is a rice product which is made from a cross-breeding between Hom Mali (Jasmine 105) rice and Hom Nil (Black Fragrant) rice, which is high in antioxidants, including beta carotene, Gamma - Orion Oryzanol, vitamin E, tannins, zinc, folate, and low in glycemic index. Therefore, the researcher studied further to develop Thai crispy rice crackers with anchovies by using Riceberry, the results show that most international tourists were satisfied and willing to consume this product. Finally, the research has created an innovative product of Thai crispy rice crackers with anchovies containing Riceberry and genuine Halal anchovies in order to establish an identity for the Muslim community in Thailand along with addressing real health 
concerns of international tourists of every nationality so that they can consume healthy food which is also tasty.

\section{References}

Booms, B.H., \& Bitner, M.J. (1981). Marketing strategies and organization structures for service firms. In J.H. Donnell, \& W.R. George (Eds.), Marketing of services. (pp. 47 - 51) Chicago: American Marketing Association.

Boone, L. E., \& Kurtz, D. L.(1998). Contemporary marketing. Cincinnati, OH: Southwestern/Thomson Learning.

Borden, N. H. (1964). The concept of the marketing mix. Journal of Advertising Research, 24(4),7-12

Drucker, P. (1973). Management: tasks, responsibilities, practices. New York: Harper \& Row.

Etzel, M. J., Walker, B. J. and Stanton, W.J. (2004). Marketing (13th ed.). New Delhi: Tata McGraw Hill.

Gilmore, A. (2003). Services marketing and management. London: Sage.

Goldsmith, R.E. (1999). The personalized marketplace: beyond the 4Ps. Marketing Intelligence and Planning, 17(4), $178-185$.

Kotler, P.(1997). Analysis planning implementation and control marketing (9th ed.). Upper Saddle River, NJ: Prentice Hall.

Kotler, P. (2003). Marketing management (11 ${ }^{\text {th }}$ ed.). Upper Saddle River, HJ: Prentice - Hall.

Lovelock, C. H., \& Wirtz, J. (2004). Services marketing (5th ed.). Upper Saddle River, NJ: Pearson Prentice Hall.

Marketing Staff of The Ohio State University. (1965). A statement of marketing philosophy. Journal of Marketing. 29(January), $43-44$.

McCarthy, J. E. (1960). Basic marketing: a managerial approach. Homewood, IL: Richard D. Irwin.

Moorthi, Y. L. R. (2002). An approach to branding services. Journal of Services. Marketing.16(2/3), 259- 275.

Needham, D.(1996). Business for higher awards. Oxford: Butterworth Heinemann.

Perrault, W., \& McCarthy, E. J. (2004). Basic marketing: A global managerial approach (15th ed.).New York: McGraw - Hill Irwin.

Vignali, C., \& Davies, B. J. (1994). The marketing mix redefined and mapped - introducing the MIXMAP model. Management Decision, $32(8), 11-16$. 